\title{
Novel primary immunodeficiency candidate genes predicted by the human gene connectome
}

\author{
Yuval $\tan ^{1 *}$ and Jean-Laurent Casanova ${ }^{1,2,3,4,5}$ \\ ${ }^{1}$ Rockefeller Branch, St. Giles Laboratory of Human Genetics of Infectious Diseases, The Rockefeller University, New York, NY, USA \\ ${ }^{2}$ Necker Branch, Laboratory of Human Genetics of Infectious Diseases, INSERM U1163, Paris, France \\ ${ }_{3}^{3}$ Imagine Institute, University Paris Descartes, Paris, France \\ ${ }^{4}$ Howard Hughes Medical Institute, New York, NY, USA \\ ${ }^{5}$ Pediatric Hematology-Immunology Unit, Necker Hospital for Sick Children, Paris, France
}

\section{Edited by:}

Fabio Candotti, CHUV - Centre

Hospitalier Universitaire Vaudois,

Switzerland

\section{Reviewed by:}

Sergio Rosenzweig, National Institutes of Health, USA

Silvia Clara Giliani, University of

Brescia, Italy

\section{*Correspondence:}

Yuval Itan, St. Giles Laboratory of Human Genetics of Infectious

Diseases, The Rockefeller University,

New York, NY, USA

e-mail: yitan@rockefeller.edu
Germline genetic mutations underlie various primary immunodeficiency (PID) diseases. Patients with rare PID diseases (like most non-PID patients and healthy individuals) carry, on average, 20,000 rare and common coding variants detected by high-throughput sequencing. It is thus a major challenge to select only a few candidate disease-causing variants for experimental testing. One of the tools commonly used in the pipeline for estimating a potential PID-candidate gene is to test whether the specific gene is included in the list of genes that were already experimentally validated as PID-causing in previous studies. However, this approach is limited because it cannot detect the PID-causing mutation(s) in the many PID patients carrying causal mutations of as yet unidentified PID-causing genes. In this study, we expanded in silico the list of potential PID-causing candidate genes from 229 to 3,110 . We first identified the top $1 \%$ of human genes predicted by the human genes connectome to be biologically close to the 229 known PID genes. We then further narrowed down the list of genes by retaining only the most biologically relevant genes, with functionally enriched gene ontology biological categories similar to those for the known PID genes. We validated this prediction by showing that 17 of the 21 novel PID genes published since the last IUIS classification fall into this group of 3,110 genes $\left(p<10^{-7}\right)$. The resulting new extended list of 3,110 predicted PID genes should be useful for the discovery of novel PID genes in patients.

Keywords: candidate gene identification, primary immunodeficiencies, the human gene connectome, disease genomics, computational biology

\section{INTRODUCTION}

Germline mutations are being found to underlie an increasing number of primary immunodeficiency (PID) diseases. With current advances, and the improved quality and decreasing cost of high-throughput sequencing (HTS), it is now possible to detect the full set of gene variants in PID patients, through techniques such as whole-exome sequencing (WES) or wholegenome sequencing (WGS). The genome of each patient contains about 20,000 coding variants and hundreds of thousands of non-coding variants (1-3). It is not straightforward to identify the PID-causing gene from the HTS data for a patient (4, 5), and the most widely used approach involves selecting known disease-causing genes as candidate genes for further investigation. Thus, in this approach, variants are identified as candidate PID-causing genes only if they concern genes already listed among those known to cause PIDs (229 such genes have been identified to date) $(6,7)$. This approach is simple to implement, but is likely to miss the true PID-causing gene in many PID patients, as novel PID genes (i.e., not already included among the 229 genes known to cause PIDs) would potentially be ignored. Alternatively, the investigator would face the nontrivial task of inferring relevant PID-candidate genes from a list of hundreds following rigorous variant-level filtering, mostly by estimating potential biological functional relatedness to the known PID genes.

To tackle the above problem, we recently described the human gene connectome (HGC) ${ }^{1}$ as the set of biological distances and routes (i.e., genes located between two genes) between all human genes, predicted in silico by a shortest distance algorithm applied to the full human genome network, conceptually similar to GPS navigation (5). The HGC and its associated user-friendly server (8) could be used to detect new candidate PID-causing genes, by ranking all genes harboring variants in PID patients on the basis of their biological proximity to already known PID genes, assuming the most highly ranked genes to be the most likely to cause PIDs.

However, a list of novel potential PID-causing gene candidates, rigorously identified on the basis of biological relevance to the PID phenotype (both by HGC-predicted biological distance to PID-causing genes and by the relevance of the candidate gene's biological function to PID), would be useful and easy for most PID investigators to use. As the HGC-predicted gene candidates may include some false positives, due to the prediction algorithm being based on protein-protein binding interactions rather than

\footnotetext{
${ }^{1}$ http://lab.rockefeller.edu/casanova/HGC
} 
biological functions associated with the gene, it is important to filter gene lists further, according to biological relevance, at the final stage of in silico prediction.

We generated a list of in silico-predicted novel PID-causing gene candidates, which we describe here. We first determined the biological clustering level of all PID genes, then used the HGC to extract the top $1 \%$ of all human genes biologically closest to all known PID genes. Finally, we selected as PID gene candidates only those genes with relevant biological functions, similar to those of known PID genes. We also show that the list of novel PID-causing gene candidates generated contains 17 of 21 recently reported PIDcausing genes (not included in the database used for prediction purposes in this study).

\section{MATERIALS AND METHODS \\ BIOLOGICAL PROXIMITY OF PID GENES: STATISTICAL SIMULATIONS}

We determined whether the 229 known PID-causing genes (6) were significantly closer to each other, biologically, than to other genes, by estimating the biological distances between all these genes (a total of 22,366 biological distance values) with the HGC and associated server $(5,8)^{2}$. We then randomly sampled one million biological distances from the set of all human genes (9), and determined, for both the PID and all-gene sets, the proportion of distances falling into the following categories: (1) small biological distances $(<10)$; (2) small-medium biological distances (between 10 and 20, 20 being the median biological distance between all human genes); (3) medium-large biological distances (between 20 and 30); (4) large-very large biological distances (between 30 and $40)$; and (5) very large-extremely large biological distances $(>40)$. We then compared the biological density of PID genes with that of other human genes, by first calculating the median distance between all 229 known PID genes, and then simulating sets of 229 randomly chosen genes, calculating the median distance between these genes, and estimating a $p$-value by determining the proportion of simulated random gene sets with a median biological distance smaller than that for the known PID genes.

\section{INITIAL EXTRACTION OF NOVEL PID-CANDIDATE GENES}

We used, as an input, the connectomes (see text footnote 1) of the 229 known PID-causing genes (6), a gene-specific connectome being defined as the set of all human genes ranked according to their biological proximity to the gene of interest. From these 229 gene-specific connectomes, we extracted only the genes in the top $1 \%$ of all human genes by $p$-value, to obtain an initial list of 29,885 genes. We then processed the novel candidate gene data in two steps, to prevent redundancy: (1) we removed all the predicted genes already in the list of 229 known PID-causing genes; and (2) we retained only one instance per novel PID-candidate gene. These two filtering steps decreased the list to 5,012 non-redundant genes.

\section{FILTERING OF PID GENE CANDIDATES BY FUNCTIONAL ENRICHMENT}

We then narrowed the list of genes down to those of biological relevance, by hypothesizing that a novel PID-causing gene would be likely to have a biological function similar to those of already

${ }^{2}$ http://hgc.rockefeller.edu/ known PID genes. For example, the gene CPN2 was predicted by the HGC biological distance to PID core gene IKBKG to be a PID candidate. However, CPN2 has the biological function of protein stabilization, which is not a biological function that is enriched in known PID genes; therefore, CPN2 could plausibly be removed from the initial list of PID-candidate genes. We therefore first used DAVID (10) to estimate the gene ontology (GO) biological functional enrichment of all known 229 PID genes. We selected only those functions for which $p<0.05$ (a total of 462 GO terms). We then applied DAVID GO biological terms analysis (11) to the PID gene candidates, and selected only genes associated with at least 1 of the 462 PID GO terms. This resulted in a final list of 3,110 in silico-predicted novel candidate PID genes.

\section{PHYLOGENY OF KNOWN AND ESTIMATED NOVEL PID GENES}

The biological-interrelatedness between the 229 known PID genes and the 3,110 candidate PID genes predicted in this study was estimated with the functional genomics alignment (FGA) phylogeny (5). We first created a biological distance matrix between all known and predicted PID genes; we then applied a neighborjoining algorithm, in the $\mathrm{R}$ statistical programing language APE (12) (analyses of phylogenetics and evolution) package nj function. Finally, we plotted a phylogenetic fan-shaped tree based on HGC-predicted biological distances between known and predicted PID genes, using the plot function of the APE package (12).

\section{GENERATION AND PLOTTING OF GENE NETWORKS}

For visual depiction of the distribution of the 229 currently known PID genes within the full human genome, we used the predicted HGC biological distance between all human genes, selecting only direct biological connections $(5,13)$ between genes, to lower the complexity of the network. We then used the NetworkX python package for complex network analyses and visualizations (14), applying the spring layout function, which estimates the localization of each gene in a two-dimensional space with the Fruchterman-Reingold force-directed algorithm (15). The nodes of known PID genes were plotted three times larger than those of the other human genes.

\section{COMPUTING RESOURCES AND PROGRAMING LANGUAGES}

This project was performed on a Mac Pro machine with 12 cores and $128 \mathrm{~GB}$ RAM. Biological distances between genes were calculated by the HGC and server. Data extraction, statistical simulations, and network analyses and visualizations were performed with the Python programing language. FGA phylogenetic analyses and visualizations were performed with the $\mathrm{R}$ programing language for statistical computing ${ }^{3}$. The programs and online server used in this study (in particular for ranking candidate genes by biological distance from core genes and FGA trees generation) are freely available to non-commercial users with step-bystep instruction at http://lab.rockefeller.edu/casanova/HGC and http://hgc.rockefeller.edu, and the scripts for the minor technical procedures in this study are all available from the authors upon request.

\footnotetext{
${ }^{3}$ http://www.r-project.org
} 


\section{RESULTS}

\section{DISTRIBUTION OF PID GENES WITHIN THE WHOLE HUMAN GENOME}

We calculated and plotted the network of all 229 known PIDcausing genes related to 50 PID syndromes (6) in the context of the full human genome (Figure 1). Using the HGC-predicted direct biological distance between human genes, we found that PID genes tend to be in the central hub of the human genome network, with only a small minority in the central hub's periphery and none in the extreme periphery of the whole human genome. PID genes are forming several tightly intra-related sub-clusters (i.e., in most

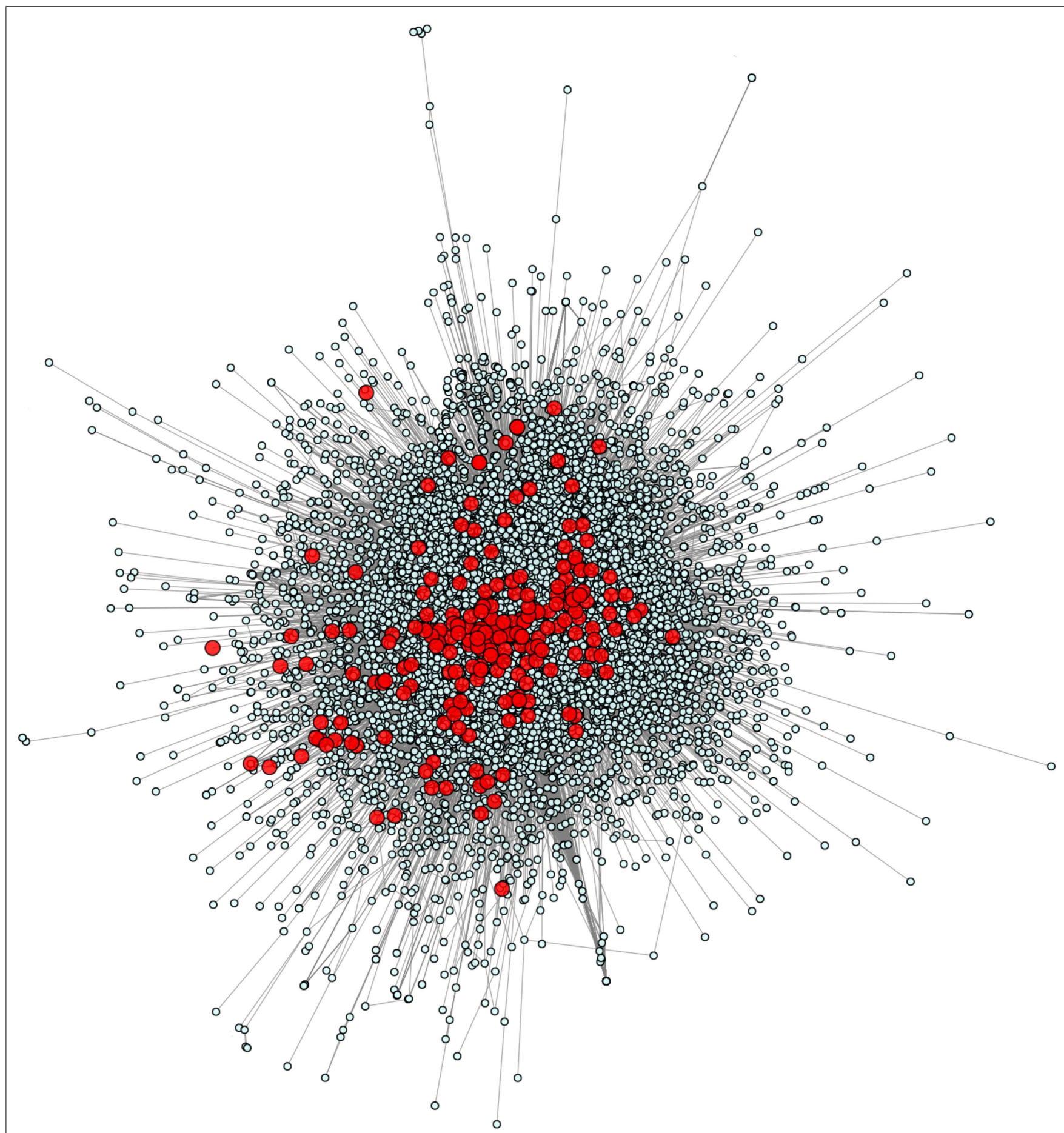

FIGURE 1 |The human genome and PID gene network. This figure shows all 229 known PID-causing genes (red) together with all 14,131 human protein-coding genes for which HGC-predicted biological distance information was available. 
cases, a PID gene will have as a close functional neighbor at least one other PID gene) across a diversity of biological mechanisms, demonstrating the variety of genetic pathways underlying PIDs.

\section{SMALL BIOLOGICAL DISTANCES BETWEEN PID GENES}

We tested the hypothesis that PID genes are functionally close to each other (which would be the prerequisite for identifying candidate PID genes on the basis of biological proximity), by comparing the biological distances between PID genes and all human genes, in terms of the proportions of biological distances assigned to five categories, from the smallest to the largest (Figure 2). Most intra-PID gene distances belonged to the very small-to-medium categories (28.4 and 53.6\%, respectively), the proportion of PID genes falling into these categories being larger than for all human genes ( 7.7 and $40.0 \%$, respectively).

We found that the median biological distance between known PID genes was 12.1, whereas that between simulated sets of 229 random genes was 20.4. None of the simulated sets of random genes had a median smaller than that of known PID genes $\left(p<10^{-7}\right)$, consistent with the hypothesis of tight functional interrelatedness between PID genes. While it was expected that genes belonging to the same pathway would display small biological distances between each other, confirming this hypothesis makes it possible to infer novel PID genes based on HGC-predicted biological distance to core PID genes.

\section{INITIAL ASSESSMENT OF NOVEL PID GENES}

Based on the demonstration that PID genes display close biological proximity, we hypothesized that currently unidentified PID genes would be located at a small biological distance from known PID genes. We therefore acquired the gene-specific connectomes of all 229 known PID-associated genes and extracted only those for

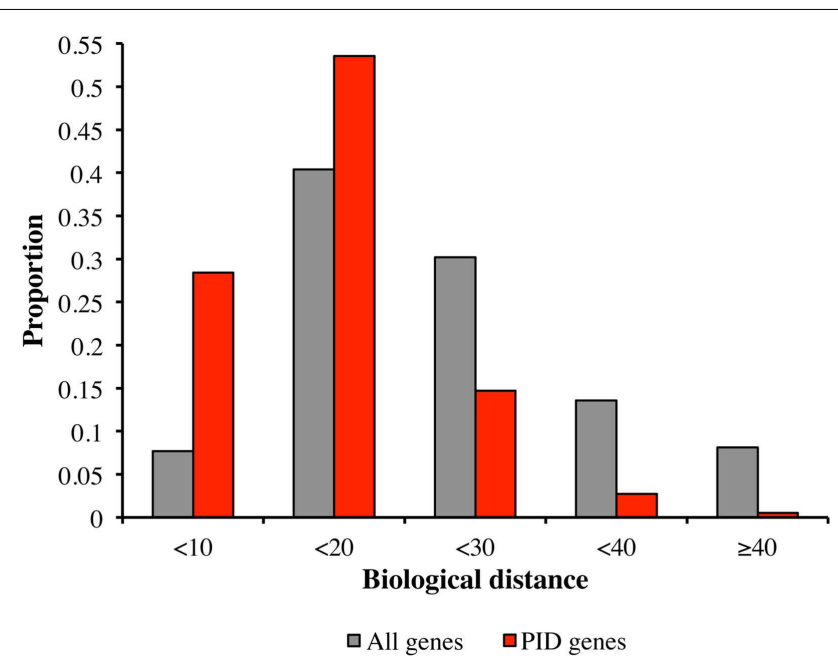

FIGURE 2 | Comparison of biological distances between PID genes and all human genes. Biological distances between PID genes (red) and all human genes (gray), according to the proportion of distances in five categories: (1) small biological distance (<10); (2) small-medium biological distance (between 10 and 20); (3) medium-large biological distance (between 20 and 30); (4) large-very large biological distance (between 30 and 40); and (5) extremely large biological distance (>40). which $p<0.01$ for connection to the respective PID gene $(29,885$ gene occurrences, many genes occur more than once due to their close biological distance to more than one known PID gene). We then removed redundant genes, and genes from the set of 229 known PID genes. This left us with 5,012 non-redundant genes not previously identified as PID genes.

\section{FINAL SET OF PROPOSED NOVEL PID-CANDIDATE GENES}

We hypothesized that most of the novel PID genes would be likely to have biological functions similar to those of known PID genes. We therefore used DAVID (10) to assess the functional enrichment, by biological GO, of all known PID genes. We retained only GO terms (11) for which $p<0.01$ (Table S1 in Supplementary Material). We then applied biological GO terms analysis to the 5,012 candidate genes identified as described above, and extracted only those with a biological function already identified among known PID genes. This generated a final list of 3,110 in silico-predicted novel candidate PID genes, identified on the basis of biological distance from known PID genes and a similar biological function, and described in terms of their relatedness to their biologically closest PID gene (Table S2 in Supplementary Material). We then carried out hierarchical clustering of all known and predicted PID genes $(5,12)$. This analysis showed that the candidate PID genes identified in this study were evenly distributed over the whole range of known PID genes (Figure 3), while they form together a network that is tightly itra-related biologically and functionally (median biological distance of 11.0, compared to 20.4 between two random human genes, $p<10^{-7}$ ).

\section{ASSESSING THE PREDICTIVE POWER OF NOVEL PID-CANDIDATE GENES}

We retrospectively demonstrated the utility of this approach for identifying novel candidate PID genes, with 21 PID genes that were recently shown experimentally to cause PIDs (7, 16-38). None were included in the list of 229 known PID genes used in this study. Seventeen of these 21 genes were included in our list of proposed 3,110 novel PID-candidate genes, with $p<10^{-7}$ (estimated by random sampling computer simulations). Moreover, similar prediction rate of 17 of 21 is achieved with the extended list of 5,012 candidates, demonstrating the usefulness of the PID gene candidates short-listing procedure presented in this study. Table 1 describes these 17 genes in terms of their relatedness to the PID gene from the connectome of which they were identified.

\section{DISCUSSION}

We describe here an extended list of 3,110 novel PID-candidate genes, initially predicted in silico with the HGC biological distance concept, then on the basis of the relevance of their biological function. We showed that PID genes (6) were significantly closer to each other biologically than other human genes. We then extracted the $1 \%$ of genes biologically closest to the known PID genes and further retained only those genes with a biological function similar to those known to display enrichment among PID genes. We generated a final in silico-predicted set of 3,110 human genes, which may be considered reliable candidate PID genes. In other words, we predict that there will be a high proportion of PID-causing genes among these 3,110 genes. We then demonstrated that 17 


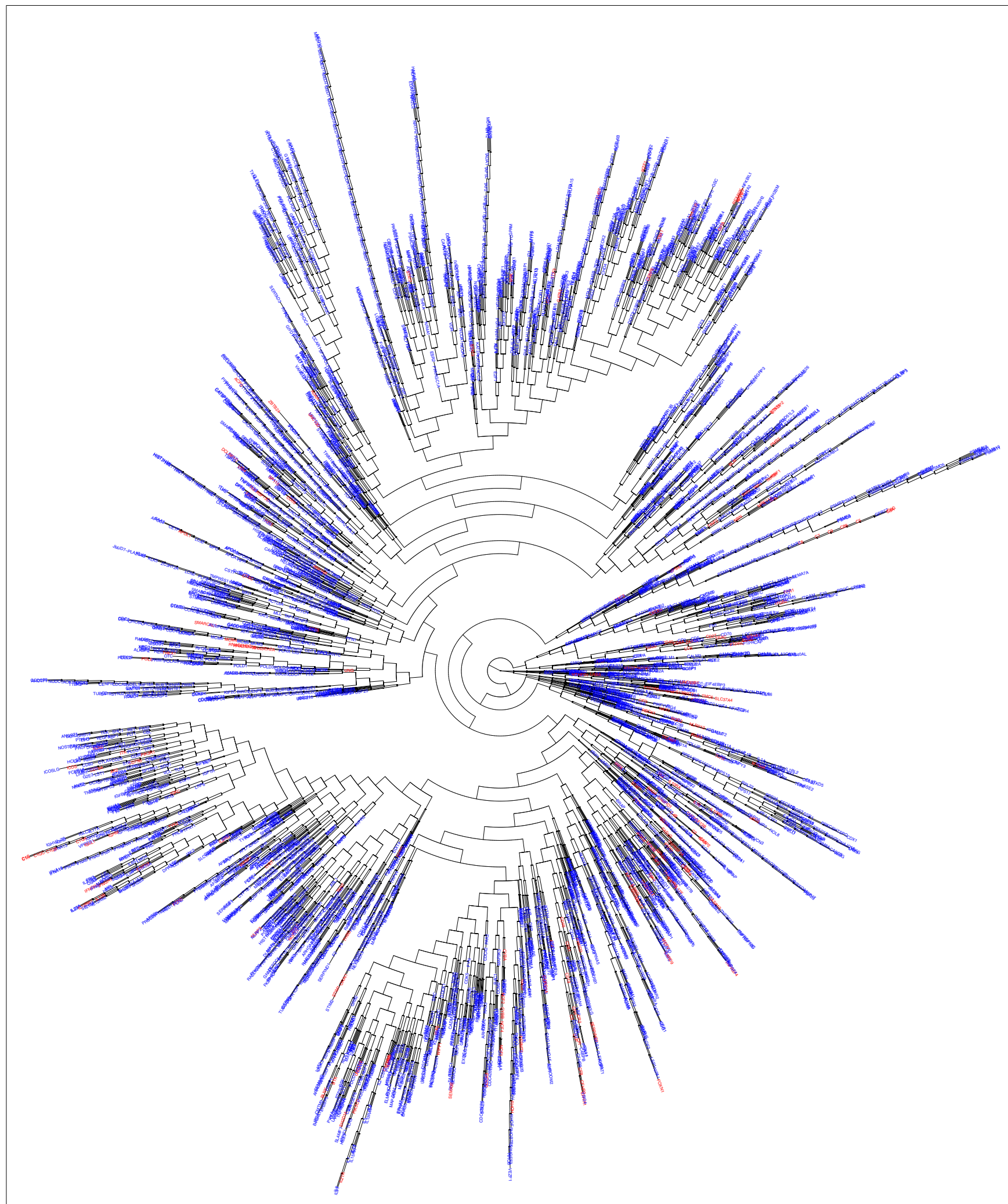

FIGURE 3 | Functional genomic alignment phylogeny of known PID genes and novel PID-candidate genes. A phylogenetic tree of biological distances generated by the functional genomic alignment method, showing hierarchical clustering of all known (red) and predicted (blue) PID genes. 
Table 1 | New PID genes predicted from the list of novel PID-candidate genes.

\begin{tabular}{|c|c|c|c|c|c|}
\hline $\begin{array}{l}\text { Predicted } \\
\text { PID gene } \\
\text { candidate }\end{array}$ & $\begin{array}{l}\text { Known } \\
\text { PID gene } \\
\text { candidate }\end{array}$ & $\begin{array}{l}\text { Biological distance } \\
\text { between candidate } \\
\text { and known }\end{array}$ & $\begin{array}{l}\text { Rank of } \\
\text { candidate } \\
\text { in known }\end{array}$ & $\begin{array}{l}p \text {-Value (percentile) } \\
\text { of candidate in } \\
\text { known }\end{array}$ & $\begin{array}{l}\text { Route between } \\
\text { candidate and } \\
\text { known }\end{array}$ \\
\hline BCL10 & CARD11 & 1.001 & 1 & 0.00007 & CARD11 $\leftrightarrow$ BCL10 \\
\hline IRF7 & MYD88 & 1.001 & 1 & 0.00007 & MYD88 ↔ IRF7 \\
\hline IL21 & IL21R & 1.001 & 1 & 0.00007 & IL21R $\leftrightarrow$ IL21 \\
\hline CTLA4 & ICOS & 1.616 & 3 & 0.00021 & $\mathrm{ICOS} \leftrightarrow \mathrm{CTLA} 4$ \\
\hline STING (TMEM173) & TBK1 & 1.001 & 3 & 0.00021 & TBK1 $\leftrightarrow$ TMEM173 \\
\hline NFKB1 & NFKBIA & 1.001 & 4 & 0.00028 & NFKBIA $\leftrightarrow$ NFKB1 \\
\hline NLRC4 & NOD2 & 1.183 & 5 & 0.00035 & NOD2 $\leftrightarrow$ NLRC4 \\
\hline NIK (MAP3K14) & CD40 & 1.064 & 8 & 0.00057 & CD40 $\leftrightarrow$ MAP3K1 \\
\hline TPP1 & TINF2 & 1.191 & 18 & 0.00127 & TINF2 ↔ TPP1 \\
\hline JAGN1 (JAG1) & CHD7 & 2.387 & 27 & 0.00191 & $\mathrm{CHD7} \leftrightarrow \mathrm{JAG} 1$ \\
\hline TGFBR2 & C8B & 6.441 & 27 & 0.00191 & $\mathrm{C} 8 \mathrm{~B} \leftrightarrow \mathrm{CLU} \leftrightarrow \mathrm{TGFBR} 2$ \\
\hline TGFBR1 & $\mathrm{C} 8 \mathrm{~B}$ & 6.441 & 28 & 0.00198 & $\mathrm{C} 8 \mathrm{~B} \leftrightarrow \mathrm{CLU} \leftrightarrow$ TGFBR1 \\
\hline INO80 & ACTB & 1.582 & 35 & 0.00248 & $\mathrm{ACTB} \leftrightarrow \mathrm{INO} 80$ \\
\hline DOCK2 & RAC2 & 1.610 & 35 & 0.00248 & RAC2 $\leftrightarrow$ DOCK2 \\
\hline STAT4 & STAT3 & 1.104 & 35 & 0.00248 & STAT3 $\leftrightarrow$ STAT4 \\
\hline ADA2 (TADA2A) & TBX1 & 7.228 & 83 & 0.00587 & TBX1 $\leftrightarrow$ C11orf30 $\leftrightarrow$ TADA2A \\
\hline $\mathrm{IFIH} 1$ & FADD & 4.141 & 87 & 0.00616 & $\mathrm{FADD} \leftrightarrow \mathrm{MAVS} \leftrightarrow \mathrm{IFIH} 1$ \\
\hline
\end{tabular}

Showing the 17 (of 21) PID genes recently reported and identified in the list of PID-candidate genes described in this study.

of 21 newly discovered PID genes were present in our proposed list of PID-candidate genes. We plan to use this list, together with the list of 229 known PID genes, in investigations of the HTS data for PID patients. A hit for one of these genes in this analysis would be associated with a higher likelihood of the gene being PID-causing.

It is important to note that as in any high-throughput genomewide analysis, the choice of input data, algorithm, and even small fine-tuning is likely to strongly affect the outcome. However, we attempted here to provide a reliable prediction where false negatives (i.e., true PID genes that are not in the final provided list of candidate genes) are minimized - an aim that is expected to be achieved by following a biologically plausible hypothesis of the tight intra-relatedness of PID genes, together with having a small number of false positives, achieved by estimating the biological relevance of the gene candidates. The main limitation of the approach described in this study is that it is still expected to contain a large number of false positives: although the final list of 3,110 genes removes about $85 \%$ of irrelevant protein-coding genes, the function of a large proportion of human genes is poorly understood. Future advances in characterizing the functions of human genes and updates to genome-wide curated databases of gene ontologies and biological/genetic pathways should significantly improve the predictive power of our (and other in silico) described methodology.

The procedures described here could be used to infer novel disease gene candidates for other disease groups. For example, as information about known cancer driver genes is available $(39)^{4}$,

\footnotetext{
${ }^{4} \mathrm{http}: / /$ cancer.sanger.ac.uk/cancergenome/projects/cosmic/
}

an extended list of cancer gene candidates could potentially be identified by HGC-predicted biological distance analysis of known cancer genes, to generate a final list of predicted novel candidates on the basis of biological function relevance. We stress that the predicted gene candidates (for PID and other diseases) should not be used for the purpose of excluding irrelevant genes, but rather to help investigators to identify novel disease-causing candidate genes. Moreover, as in any other in silico prediction methodology, in order for a mutation in a candidate gene to be confirmed as disease-causing, it must be verified by experimental immunological and genetic approaches, due to the complex nature of genetic disease pathogenesis, which in many cases involves phenotypic heterogeneity and incomplete penetrance, which current in silico methods cannot predict. We believe that rigorous use of the extended in silico-predicted list of candidate PID genes would increase the rate of novel PID-gene discovery in high throughput sequencing studies (40).

\section{AUTHOR CONTRIBUTIONS}

YI initiated the study, analyzed the data, and wrote the article. JC supervised the study, assisted with data resources, and wrote the article.

\section{ACKNOWLEDGMENTS}

We thank Laurent Abel, Capucine Picard, Bertrand Boisson, ShenYing Zhang, Stephanie Boisson-Dupuis, Anne Puel, Jacinta Bustamante, Emmanuelle Jouanguy, Xiao-Fei Kong, Janet Markle, and Guillaume Vogt for sharing known and novel PID gene data and advice. We thank Yelena Nemirovskaya and Eric Anderson for administrative support. YI was supported in part by grant \# UL1 TR000043 from the National Center for Advancing Translational 
Sciences (NCATS), National Institutes of Health (NIH) Clinical and Translational Science Award (CTSA) program. This study was supported by the Rockefeller University and the St. Giles Foundation.

\section{SUPPLEMENTARY MATERIAL}

The Supplementary Material for this article can be found online at http://journal.frontiersin.org/article/10.3389/fimmu. 2015.00142

Table S1 | Functional enrichment of known PID genes. Biological GO enrichment categories $(p<0.05)$ for the 229 known PID genes. Other categories include GO accession term and number, fold-enrichment for the PID gene set for the specific GO term, and set of known PID genes for the specific GO term

Table S2 | Proposed novel candidate PID genes. The end result of this study is shown in 3,110 novel candidate PID-causing genes predicted in silico (column A). Column B corresponds to the known PID gene closest to the predicted novel PID gene. Other categories, by column: (C) biological distance between the known and predicted PID genes; (D) the rank of the predicted PID gene in the connectome of the known PID gene; (E) p-value for biological proximity of the predicted PID gene in the connectome of the known PID gene; $(F)$ the predicted route (i.e., the genes on the shortest predicted route) between the known and predicted PID genes; and (G) the degrees of separation (i.e., the number of direct connections on the route) between the known and predicted PID genes.

\section{REFERENCES}

1. Goldstein DB, Allen A, Keebler J, Margulies EH, Petrou S, Petrovski S, et al. Sequencing studies in human genetics: design and interpretation. Nat Rev Genet (2013) 14:460-70. doi:10.1038/nrg3455

2. Metzker ML. Sequencing technologies - the next generation. Nat Rev Genet (2010) 11:31-46. doi:10.1038/nrg2626

3. Bamshad MJ, Ng SB, Bigham AW, Tabor HK, Emond MJ, Nickerson DA, et al. Exome sequencing as a tool for Mendelian disease gene discovery. Nat Rev Genet (2011) 12:745-55. doi:10.1038/nrg3031

4. Casanova JL, Abel L. The genetic theory of infectious diseases: a brief history and selected illustrations. Annu Rev Genomics Hum Genet (2013) 14:215-43. doi:10.1146/annurev-genom-091212-153448

5. Itan Y, Zhang SY, Vogt G, Abhyankar A, Herman M, Nitschke P, et al. The human gene connectome as a map of short cuts for morbid allele discovery. Proc Natl Acad Sci U S A (2013) 110:5558-63. doi:10.1073/pnas.1218167110

6. Al-Herz W, Bousfiha A, Casanova JL, Chatila T, Conley ME, CunninghamRundles C, et al. Primary immunodeficiency diseases: an update on the classification from the international union of immunological societies expert committee for primary immunodeficiency. Front Immunol (2014) 5:162. doi:10.3389/ fimmu.2014.00162

7. Casanova JL, Conley ME, Seligman SJ, Abel L, Notarangelo LD. Guidelines for genetic studies in single patients: lessons from primary immunodeficiencies. $J$ Exp Med (2014) 211:2137-49. doi:10.1084/jem.20140520

8. Itan Y, Mazel M, Mazel B, Abhyankar A, Nitschke P, Quintana-Murci L, et al. HGCS: an online tool for prioritizing disease-causing gene variants by biological distance. BMC Genomics (2014) 15:256. doi:10.1186/1471-2164-15-256

9. Flicek P, Ahmed I, Amode MR, Barrell D, Beal K, Brent S, et al. Ensembl 2013. Nucleic Acids Res (2013) 41:D48-55. doi:10.1093/nar/gks1236

10. Huang da W, Sherman BT, Lempicki RA. Systematic and integrative analysis of large gene lists using DAVID bioinformatics resources. Nat Protoc (2009) 4:44-57. doi:10.1038/nprot.2008.211

11. Ashburner M, Ball CA, Blake JA, Botstein D, Butler H, Cherry JM, et al. Gene ontology: tool for the unification of biology. The gene ontology consortium. Nat Genet (2000) 25:25-9. doi:10.1038/75556

12. Paradis E, Claude J, Strimmer K. APE: analyses of phylogenetics and evolution in R language. Bioinformatics (2004) 20:289-90. doi:10.1093/bioinformatics/ btg 412
13. Franceschini A, Szklarczyk D, Frankild S, Kuhn M, Simonovic M, Roth A, et al. STRING v9.1: protein-protein interaction networks, with increased coverage and integration. Nucleic Acids Res (2013) 41:D808-15. doi:10.1093/ nar/gks1094

14. Hagberg AA, Schult DA, Swart PJ. Exploring Network Structure, Dynamics, and Function Using NetworkX. In: Varoquaux G, Vaught T, Millman J, editors. Proceedings of the 7th Python in Science Conference (SciPy2008). Pasadena, CA (2008). p. 11-5.

15. Fruchterman TMJ, Reingold EM. Graph drawing by force-directed placement. Softw Pract Exp (1991) 21:1129-64.

16. Mousallem T, Yang J, Urban TJ, Wang H, Adeli M, Parrott RE, et al. A nonsense mutation in IKBKB causes combined immunodeficiency. Blood (2013) 124:2046-50. doi:10.1182/blood-2014-04-571265

17. Willmann KL, Klaver S, Dogu F, Santos-Valente E, Garncarz W, Bilic I, et al. Biallelic loss-of-function mutation in NIK causes a primary immunodeficiency with multifaceted aberrant lymphoid immunity. Nat Commun (2014) 5:5360. doi:10.1038/ncomms6360

18. Torres JM, Martinez-Barricarte R, García-Gómez S, Mazariegos MS, Itan Y, Boisson B, et al. Inherited BCL10 deficiency impairs hematopoietic and nonhematopoietic immunity. J Clin Invest (2014) 124:5239-48. doi:10.1172/ JCI77493

19. Martin E, Palmic N, Sanquer S, Lenoir C, Hauck F, Mongellaz C, et al. CTP synthase 1 deficiency in humans reveals its central role in lymphocyte proliferation. Nature (2014) 510:288-92. doi:10.1038/nature13386

20. Chakraborty PK, Schmitz-Abe K, Kennedy EK, Mamady H, Naas T, Durie D, et al. Mutations in TRNT1 cause congenital sideroblastic anemia with immunodeficiency, fevers, and developmental delay (SIFD). Blood (2014) 124:2867-71. doi:10.1182/blood-2014-08-591370

21. Kocak H, Ballew BJ, Bisht K, Eggebeen R, Hicks BD, Suman S, et al. HoyeraalHreidarsson syndrome caused by a germline mutation in the TEL patch of the telomere protein TPP1. Genes Dev (2014) 28:2090-102. doi:10.1101/gad. 248567.114

22. Kracker S, Di Virgilio M, Schwartzentruber J, Cuenin C, Forveille M, Deau MC, et al. An inherited immunoglobulin class-switch recombination deficiency associated with a defect in the INO80 chromatin remodeling complex. J Allergy Clin Immunol (2014). doi:10.1016/j.jaci.2014.08.030

23. Zhang Q, Ji XW, Hou XM, Lu FM, Du Y, Yin JH, et al. Effect of functional nuclear factor-kappaB genetic polymorphisms on hepatitis $B$ virus persistence and their interactions with viral mutations on the risk of hepatocellular carcinoma. Ann Oncol (2014) 25:2413-9. doi:10.1093/annonc/mdu451

24. Schubert D, Bode C, Kenefeck R, Hou TZ, Wing JB, Kennedy A, et al. Autosomal dominant immune dysregulation syndrome in humans with CTLA4 mutations. Nat Med (2014) 20:1410-6. doi:10.1038/nm.3746

25. Salzer E, Kansu A, Sic H, Májek P, Ikinciogullari A, Dogu FE, et al. Earlyonset inflammatory bowel disease and common variable immunodeficiency-like disease caused by IL-21 deficiency. J Allergy Clin Immunol (2014) 133(16511659):e1612. doi:10.1016/j.jaci.2014.02.034

26. Kuehn HS, Ouyang W, Lo B, Deenick EK, Niemela JE, Avery DT, et al. Immune dysregulation in human subjects with heterozygous germline mutations in CTLA4. Science (2014) 345:1623-7. doi:10.1126/science.1255904

27. Jeremiah N, Neven B, Gentili M, Callebaut I, Maschalidi S, Stolzenberg MC, et al. Inherited STING-activating mutation underlies a familial inflammatory syndrome with lupus-like manifestations. J Clin Invest (2014) 124:5516-20. doi:10.1172/JCI79100

28. Rice GI, del Toro Duany Y, Jenkinson EM, Forte GM, Anderson BH, Ariaudo G, et al. Gain-of-function mutations in IFIH1 cause a spectrum of human disease phenotypes associated with upregulated type I interferon signaling. Nat Genet (2014) 46:503-9. doi:10.1038/ng.2933

29. Zhou Q, Yang D, Ombrello AK, Zavialov AV, Toro C, Zavialov AV, et al. Earlyonset stroke and vasculopathy associated with mutations in ADA2. N Engl J Med (2014) 370:911-20. doi:10.1056/NEJMoa1307361

30. Navon Elkan P, Pierce SB, Segel R, Walsh T, Barash J, Padeh S, et al. Mutant adenosine deaminase 2 in a polyarteritis nodosa vasculopathy. $N$ Engl J Med (2014) 370:921-31. doi:10.1056/NEJMoa1307362

31. Ciancanelli MJ, Huang S, Luthra P, Garner H, Itan Y, Volpi S, et al. Lifethreatening influenza and impaired interferon amplification in human IRF7 deficiency. Science (2015). (in press). 
32. Dobbs K, Domínguez CC, Zhang SY, Parolini S, Audry M, Chou J, et al. Human DOCK2 mutations underlie an autosomal recessive pleiotropic immunodeficiency with early-onset invasive infections. $N$ Engl J Med (in press).

33. Boztug K, Järvinen PM, Salzer E, Racek T, Mönch S, Garncarz W, et al. JAGN1 deficiency causes aberrant myeloid cell homeostasis and congenital neutropenia. Nat Genet (2014) 46:1021-7. doi:10.1038/ng.3069

34. Naviglio S, Arrigo S, Martelossi S, Villanacci V, Tommasini A, Loganes C, et al. Severe inflammatory bowel disease associated with congenital alteration of transforming growth factor beta signaling. J Crohns Colitis (2014) 8:770-4. doi:10.1016/j.crohns.2014.01.013

35. Sadat MA, Moir S, Chun TW, Lusso P, Kaplan G, Wolfe L, et al. Glycosylation, hypogammaglobulinemia, and resistance to viral infections. NEngl J Med (2014) 370:1615-25. doi:10.1056/NEJMoa1302846

36. Sassi A, Lazaroski S, Wu G, Haslam SM, Fliegauf M, Mellouli F, et al. Hypomorphic homozygous mutations in phosphoglucomutase 3 (PGM3) impair immunity and increase serum IgE levels. J Allergy Clin Immunol (2014) 133:e1-3. doi:10.1016/j.jaci.2014.02.025

37. Zhang Y, Yu X, Ichikawa M, Lyons JJ, Datta S, Lamborn IT, et al. Autosomal recessive phosphoglucomutase 3 (PGM3) mutations link glycosylation defects to atopy, immune deficiency, autoimmunity, and neurocognitive impairment. J Allergy Clin Immunol (2014) 133:e1-5. doi:10.1016/j.jaci.2014.02.013

38. Aavikko M, Kaasinen E, Nieminen JK, Byun M, Donner I, Mancuso R, et al. Whole genome sequencing identifies STAT4 as a putative susceptibility gene in classic Kaposi sarcoma. J Infect Dis (2014) pii:jiu667. doi:10.1093/infdis/jiu667
39. Forbes SA, Bindal N, Bamford S, Cole C, Kok CY, Beare D, et al. COSMIC: mining complete cancer genomes in the catalogue of somatic mutations in cancer. Nucleic Acids Res (2011) 39:D945-50. doi:10.1093/nar/gkq929

40. Belkadi A, Bolze A, Itan Y, Cobat A, Vincent QB, Antipenko A, et al. Wholegenome sequencing is more powerful than whole-exome sequencing for detecting exome variants. Proc Natl Acad Sci (2015). (in press).

Conflict of Interest Statement: The authors declare that the research was conducted in the absence of any commercial or financial relationships that could be construed as a potential conflict of interest.

Received: 16 December 2014; accepted: 15 March 2015; published online: 01 April 2015. Citation: Itan Y and Casanova J-L (2015) Novel primary immunodeficiency candidate genes predicted by the human gene connectome. Front. Immunol. 6:142. doi: 10.3389/fimmu.2015.00142

This article was submitted to Primary Immunodeficiencies, a section of the journal Frontiers in Immunology.

Copyright $\odot 2015$ Itan and Casanova. This is an open-access article distributed under the terms of the Creative Commons Attribution License (CC BY). The use, distribution or reproduction in other forums is permitted, provided the original author(s) or licensor are credited and that the original publication in this journal is cited, in accordance with accepted academic practice. No use, distribution or reproduction is permitted which does not comply with these terms. 